\title{
La autorregulación de las marcas de juegos de azar online a través de su publicidad en televisión
}

\section{The self-regulation of online gambling brands through their television advertising}

\author{
Luis Mañas-Viniegra \\ Universidad Complutense de Madrid, España \\ Imanas@ucm.e
}

Recibido: 25-02-2018

Aceptado: 02-04-2018

Resumen

Los juegos de azar representan el 2,5\% del PIB español, concentrándose en 18 anunciantes la inversión publicitaria en televisión de los juegos de azar online. El objetivo de la investigación es determinar el cumplimiento del Código de Conducta sobre Comunicaciones Comerciales de las Actividades del Juego, realizando un análisis de contenido a partir de 24 variables aplicadas a una muestra de 60 anuncios emitidos en televisión, considerando los riesgos para la salud que puede provocar el juego online en colectivos vulnerables. El 90\% no incluye el logo "jugar bien", el 78,33\%, el de "autoexclusión" y el 11,67\%, el de "+18". Aunque aparecen comportamientos relacionados con el juego irresponsable y un uso desmesurado de los bonos de bienvenida, el principal incumplimiento afecta a la igualdad de género.

Palabras clave: Autocontrol, autorregulación, juegos de azar, póquer online, publicidad.

\section{Abstract}

Gambling represents $2.5 \%$ of the Spanish GDP, and the investment in television advertising of online gambling is concentrated in 18 advertisers. The objective of this research is to determine compliance with the Code of Conduct for Commercial Communication of Gambling Activities by performing a content analysis using 24 variables applied to a sampling of 60 advertisements broadcast on television, and also to consider the health risks of online gambling to vulnerable groups. Of the advertisements studied, $90 \%$ do not include the "play responsibly" logo, 78.33\% do not show the "self-exclusion" logo, and $11.67 \%$ do not have the "+18" logo. Even though behaviour related to irresponsible gambling is shown in the advertising, and there is an excessive use of welcome bonuses, the main noncompliance affects gender equality.

Key words: Advertising, Autocontrol, Gambling, Online poker, Self-regulation.

Sumario

1. Introducción | 1.1. La inversión publicitaria del sector | 1.2. La autorregulación del sector | 2. Material y métodos | 2.1. Objetivos | 2.2. Hipótesis | 2.3. Metodología | 3. Resultados | 4. Discusión y conclusiones | Referencias bibliográficas | Anexo

\section{Cómo citar este artículo}

Mañas-Viniegra, M. (2018): "La autorregulación de las marcas de juegos de azar online a través de su publicidad en televisión", methaodos.revista de ciencias sociales, 6 (1): 16-37. http://dx.doi.org/10.17502/m.rcs.v6i1.210 


\section{Introducción}

El sector de los juegos de azar en España representa el 2,5\% del PIB, según datos de la Dirección General de Ordenación del Juego (DGOJ, 2016), alcanzando los ingresos de los juegos online un 26,5\% sobre el total, con crecimientos anuales superiores al 10\%. 676.322 usuarios jugaron online de media durante el cuarto trimestre de 2017, con un aumento del 11,87\% con respecto al año anterior (DGOJ, 2017). Se consideran juegos online los sujetos a la concesión de autorizaciones y licencias por parte de la DGOJ, es decir, póquer, casino, apuestas deportivas, bingo, concursos y sus variedades específicas, estando expresamente excluidos los juegos de lotería sujetos a reserva, que son los promovidos por la Sociedad Estatal de Loterías y Apuestas del Estado (SELAE) y la Organización Nacional de Ciegos Españoles (ONCE). El perfil del jugador online en España (DGOJ, 2016a) es el de un hombre -83\% de los jugadores activos- de entre 26 y 35 años que reparte su actividad entre las apuestas deportivas, el póquer y el casino online. Por su parte, las mujeres, con una franja de edad entre 36 y 45 años, centran su actividad en el bingo online y todos ellos se encuentran en la clase social media-alta (42,6\%) y el 27,9\%, en la media-media (Gómez et al., 2017).

Numerosos autores han puesto de manifiesto los desajustes emocionales, conductuales y cognitivos que provocan los juegos de azar, que desestructuran las relaciones sociales, familiares y laborales y alteran gravemente la economía doméstica, aunque los juegos de azar online presentan mayores riesgos, habiendo facilitado la confluencia de las variables principales en la expansión social de cualquier adicción: la disponibilidad, accesibilidad (Grun y McKeigue, 2000; Nutt, et al., 2010) y comodidad (Derevensky y Gupta, 2007), falta de control físico y una intensa publicidad de apuestas deportivas, casino y póquer online (Chóliz y Lamas, 2017), que se consideran más adictivos que los propios juegos físicos para el público más joven (Chóliz, 2016). Pese a la prohibición de que los menores participen en el juego, la realidad revela que el $62,1 \%$ ha practicado algún juego de azar en el último año, especialmente las apuestas deportivas (Chóliz y Lamas, 2017).

\subsection{La inversión publicitaria del sector}

Infoadex (Sánchez Revilla, 2017: 33) establece que el sector Juegos y Apuestas ocupa el undécimo lugar en cuanto a la inversión publicitaria, que asciende a 150 millones de euros (MM.EE.) y representa el 3,6\% del total del mercado publicitario en España.

Tabla 1. Inversión publicitaria por sector en España

\begin{tabular}{lcccccc}
\hline & \multicolumn{3}{c}{2016} & \multicolumn{3}{c}{2015} \\
\cline { 2 - 7 } Sector & Inv. (MM.EE.) & $\%$ & $N^{\circ}$ marcas & Inv. (MM.EE.) & $\%$ & $N^{\circ}$ marcas \\
\hline Distribución y Restauración & 490,9 & 11,7 & 12.212 & 437,5 & 10,9 & 12.097 \\
Automoción & 469,7 & 11,2 & 8.614 & 411,4 & 10,2 & 7.819 \\
Finanzas & 398,1 & 9,5 & 2.683 & 398,1 & 9,9 & 2.588 \\
Alimentación & 351,9 & 8,4 & 3.432 & 329,1 & 8,2 & 3.176 \\
Belleza e Higiene & 349,8 & 8,4 & 1.975 & 351,8 & 8,7 & 1.829 \\
Servicios Públicos y Privados & 311,0 & 7,4 & 16.635 & 302,6 & 7,5 & 16.682 \\
Cultura, Enseñanza y Medios Com. & 279,5 & 6,7 & 22.849 & 292,8 & 7,3 & 22.986 \\
Telecomunicaciones e Internet & 260,2 & 6,2 & 1.444 & 258,9 & 6,4 & 1.578 \\
Transporte, Viajes y Turismo & 197,4 & 4,7 & 7.706 & 185,6 & 4,6 & 6.311 \\
Bebidas & 169,3 & 4,0 & 2.190 & 157,3 & 3,9 & 2.053 \\
Juegos y Apuestas & 150,0 & 3,6 & 293 & 127,7 & 3,2 & 263 \\
\hline
\end{tabular}

Fuente: Infoadex (2017). 
El sector destaca por su atomización, con sólo 293 anunciantes y, a pesar de ello, es el que concentra el mayor número de anunciantes con inversiones superiores a $450.000 €$, veinticuatro, cuya inversión representa el 98,3\% del sector. En cuanto a la inversión en televisión, asciende a 60.059.510 €, un $2,8 \%$ sobre el total de los anunciantes en este medio convencional, con 39 anunciantes del sector, de los cuales 18 concentran el 98,3\% de la inversión del sector superior a $450.000 €$ en este medio.

El Consejo Audiovisual de Andalucía (2017) identificó a partir de datos de Kantar Media la publicidad del juego online emitida durante un mes -entre el 10 de noviembre y el 10 de diciembre de 2017- en las televisiones nacionales 1 en abierto: 4.519 anuncios sobre apuestas deportivas, casino, póquer y bingo online, de los cuales el 57,24\% corresponde a apuestas deportivas.

Tabla 2. Anuncios emitidos en televisión de juegos de azar online

\begin{tabular}{lcc}
\hline Anunciante & Inserciones & $\%$ \\
\hline Pokerstars & 1.280 & $28,32 \%$ \\
888 & 1.222 & $27,04 \%$ \\
Tómbola & 464 & $10,27 \%$ \\
Codere & 397 & $8,79 \%$ \\
Premier Casino & 337 & $7,46 \%$ \\
Yobingo & 276 & $6,11 \%$ \\
Sportium & 205 & $4,54 \%$ \\
Carcaj & 107 & $2,37 \%$ \\
Wanabet & 65 & $1,44 \%$ \\
Canal Bingo & 64 & $1,42 \%$ \\
Bet365 & 46 & $1,02 \%$ \\
Gran Hermano Bingo & 24 & $0,53 \%$ \\
Betfair & 12 & $0,27 \%$ \\
William Hill & 12 & $0,27 \%$ \\
Bwin & 6 & $0,13 \%$ \\
Intertwetten & 2 & $0,04 \%$ \\
\hline Total & 4.519 & $100,00 \%$ \\
\hline
\end{tabular}

Fuente: Elaboración a partir de Consejo Audiovisual de Andalucía (2017).

La distribución de las inserciones de apuestas deportivas online se concentra en Gol TV (31,4\%), La Sexta (8\%) y Neox (7,7\%), mientras que casino, póquer y bingo online se emiten en FDF-T5 $(9,5 \%)$, Telecinco $(9,2 \%)$ y BeMADtv $(9,1 \%)$.

\subsection{La autorregulación del sector}

La Ley 34/1998, de 11 de noviembre, General de Publicidad ya consideraba a los juegos de suerte, envite o azar como una actividad con riesgos derivados para la salud o la seguridad en el patrimonio (Ley 34, 1998: art. 8), cuestión que se concretó en la Ley 13/2011, de 27 de mayo, de Regulación del Juego al establecer que sólo podrán realizar promoción de tal actividad los operadores habilitados por la autoridad competente (Ley 13, 2011: art. 7), prohibiendo el acceso a los menores de edad (Ley 13, 2011: art. 6), debiendo realizar acciones de responsabilidad social que permitan difundir "actitudes de juego moderado, no compulsivo y responsable" (Ley 13, 2011: art. 8).

\footnotetext{
${ }^{1}$ Aunque el informe analiza también a la televisión pública andaluza, ésta no emitió ningún anuncio de juegos de azar online.
} 
El reconocimiento de la necesidad de un sistema de autorregulación de la publicidad del sector (Ley 13, 2011: art. 24.5) se concreta en el desarrollo de la Ley 13/2011 que realiza el Real Decreto 1614/2011, de 14 de noviembre, y la posterior firma entre Autocontrol y la DGOJ del Código de Conducta sobre Comunicaciones Comerciales de las Actividades del Juego (Autocontrol, 2012), que se estructura en torno a 8 grandes principios en lo que a publicidad se refiere, en consonancia con lo expresado en la Ley:

- $\quad$ Principio de legalidad, por el que su contenido se adecuará a la normativa vigente.

- $\quad$ Principio de lealtad, respetando la buena fe y buenos usos mercantiles.

- Principio de identificación, permitiendo que se identifique de manera clara y sencilla la publicidad como tal.

- Principio de veracidad, sin inducir a error ni omitir datos esenciales que induzcan ese error.

- Principio de responsabilidad social, evitando incitar comportamientos antisociales o violentos, socialmente irresponsables, que puedan causar algún perjuicio económico, social o emocional, que minusvalore el esfuerzo en el trabajo y en el estudio en relación al juego o que tolere el juego en un entorno laboral. Además, el contenido no puede sugerir que el juego mejore las habilidades personales, el reconocimiento social, el atractivo seductor o sexual o sea algo prioritario en la vida. En cuanto a las relaciones sociales reflejadas en la publicidad, el grupo no puede forzar al individuo para jugar o menospreciar de algún modo una abstinencia jugadora, no pueden supeditar las relaciones sociales o familiares como secundarias al juego ni denigrar a las personas que no juegan o ensalzar socialmente a quienes sí lo hacen. Desde el 12 de marzo de 2013 es obligatorio incluir la leyenda "Juega con responsabilidad" junto al logo de "Juego Seguro", que acredita que el operador está habilitado para prestar el servicio.

- Principio de juego responsable, prohibiendo incitar a una práctica adictiva o patológica, sugerir que es la solución a cualquier tipo de problema o que su abuso no tiene consecuencias perniciosas y obligando a incluir un mensaje de juego responsable. También prohíbe la posibilidad de incitar al juego mediante la concesión de ofertas de crédito, sugiriendo que jugar más, tener más habilidades o experiencia aumenta las probabilidades de ganar o que las apuestas descontroladas o compulsivas sean gratificantes.

- Protección de menores: el juego está reservado a los mayores de 18 años, por lo que no se puede realizar publicidad dirigida a ellos y sólo podrá emitirse entre las 22:00 y las 6:00 horas la publicidad de póquer, casino y apuestas deportivas online. Sin embargo, la publicidad relacionada con el bingo y las apuestas mutuas sólo deberán emitirse fuera de las franjas de protección reforzada (Ley 7, 2010: art. 7.2). La excepción también afecta a las apuestas deportivas, cuya publicidad se puede emitir durante la retransmisión de los propios acontecimientos deportivos.

La publicidad engañosa se encuentra recogida tanto en las diferentes leyes del sector como en la norma 14 del Código de Autocontrol (2011) y ha sido señalada por el jurado de Autocontrol al identificar publicidad que genere "una expectativa errónea al consumidor" (Autocontrol, 2017: 3) o al aclarar que "la publicidad que aparece de un modo destacado en la misma no puede verse limitada de forma relevante o significativamente contradicha por otros mensajes menos destacados que impiden que el consumidor pueda comprender adecuadamente el contenido y el alcance real" (Autocontrol, 2017: 4). En el póquer, las habituales bonificaciones que se ofrecen a los jugadores en su primera inscripción o participación no pueden inducir a la confusión sobre la naturaleza del juego (Orden EHA/3089, 2011: art. 9), aunque las condiciones de aplicación y el periodo de vigencia de la promoción sólo sea obligatorio que aparezcan en la plataforma de juego, al igual que sucede en el bingo (Orden EHA/3087, 2011) y las apuestas cruzadas (Orden HAP/1369, 2014). La Comisión Nacional del Juego es quien tiene la potestad de limitar el importe máximo de estas bonificaciones o promociones. A pesar de que en 2015 se presentó un Proyecto de Real Decreto de Comunicaciones Comerciales de las Actividades de Juego y Juego Responsable y se sometió a información pública, éste no fue tramitado. 
Los anunciantes de juegos de azar online recurrieron inicialmente al patrocinio de equipos de fútbol como método para alcanzar masivamente a los públicos (Chico y Ruiz, 2013) y, desde entonces, ha sido discutido el propio papel de la promoción de los juegos de azar online como fomento de una actividad de ocio (McMullan y Miller, 2010), que podría llegar a ser percibida como un entretenimiento sin efectos nocivos (Lamont et al., 2011; Buil et al., 2015).

En efecto, se ha constatado que los conocidos como bonos de bienvenida facilitan el acceso al juego online al no existir la barrera del dinero físico ni la necesidad de acreditarse como mayor de edad más allá de la aportación de un número de documento (Consell de l'Audiovisual de Catalunya, 2017). Precisamente porque se han producido algunos casos de malas prácticas en el sector, que son evidentes en el momento en el que las propias notas de prensa de los operadores líderes destacan "sus compromisos con el cliente, con bonos sin trampa, pago inmediato de las apuestas ganadoras y sin vetarle si gana" (Codere, 2017), una correcta aplicación del código de autorregulación aceptado voluntariamente por los operadores autorizados es la mejor garantía de que la publicidad del sector sea responsable y cumpla, simultáneamente, su finalidad promocional.

El análisis realizado por el Consejo Audiovisual de Andalucía (2017) durante un mes, más extenso que el realizado durante una semana y sólo en una selección de cadenas de televisión por el Consell de l'Audiovisual de Catalunya (2017), corrobora que no se emitió ningún anuncio de juego online durante el horario reforzado de protección de menores, pero sí dentro del horario prohibido de protección entre las $6: 00$ y las $22: 00$, en concreto el $13 \%$ de los anuncios de apuestas deportivas y el $22 \%$ de juegos de azar online. En cualquier caso, hay que considerar que esto no implica incumplir el Código de Conducta, puesto que GolTV, por ejemplo, ofrece precisamente en este horario las competiciones deportivas que permiten insertar anuncios sobre apuestas deportivas online durante su emisión. El análisis cualitativo del estudio se limitaba a 5 anuncios publicitarios en televisión con la única variable de si se cumplía o no el principio de veracidad, concluyendo que dos de los cinco no lo cumplía, William Hill y Bet365. Consecuentemente, y partiendo de la importancia del estudio cuantitativo realizado, la presente investigación tiene como objetivo aportar el análisis cualitativo que complemente esos datos cuantitativos sobre la publicidad emitida en televisión.

\section{Material y métodos}

Esta investigación cualitativa aplica un análisis de contenido a la publicidad convencional emitida en televisión por parte de operadores autorizados del sector de juegos de azar online. Excluimos del análisis, por tanto, la autopromoción de los programas de televisión y los anuncios de SELAE y ONCE, así como otras formas publicitarias o publicidad en otros medios.

\subsection{Objetivos}

El objetivo general es determinar el grado de cumplimiento de las leyes y códigos deontológicos vigentes que afectan al sector.

Los objetivos específicos son los siguientes:

- Determinar el grado de cumplimiento de las variables analizadas.

- Desarrollar los principales motivos de incumplimiento.

- Establecer una conexión entre los incumplimientos generales del sector y los de las empresas individualmente.

- Establecer casos de estudio de cumplimiento de prácticas responsables.

- Concluir unas recomendaciones de mejora del actual código de autorregulación. 


\subsection{Hipótesis}

La hipótesis de partida es que la mayoría de los anunciantes del sector cumplen lo regulado por las leyes y los códigos deontológicos, a pesar de utilizar frases ambiguas para provocar una interpretación en los públicos que sí supondrían un incumplimiento de formularse de un modo expreso y directo.

\subsection{Metodología}

Partiendo del universo formado por los 39 anunciantes totales del sector Juegos y Apuestas en televisión (Infoadex, 2017), y una vez eliminadas las diferentes marcas de SELAE, ONCE, autopromoción de los programas de televisión y otros juegos de azar tradicionales conforme a los objetivos de la investigación, la muestra de análisis queda formada por los 16 anunciantes identificados por el Consejo Audiovisual de Andalucía (2017) en diciembre de 2017 recogidos en la tabla $n^{\circ}$ 2. Se ha omitido en el análisis a Gran Hermano Bingo por estar vinculado a un programa de televisión y, consecuentemente, ser un anunciante de autopromoción efímero y se han incluido a otros cuatro anunciantes que tienen presencia a lo largo del año (Paf, Luckia, Marca Apuestas y Cirsa), ponderando el número de spots publicitarios analizados en función de la inversión publicitaria de cada anunciante reflejada por Infoadex.

El corpus de análisis dentro de la muestra final queda constituido por 60 anuncios elegidos al azar dentro del periodo de cinco años 2013-2017 de dichos anunciantes, puesto que en la fase preliminar se detectó que hay pocos cambios en la creatividad de cada campaña cada año, de modo que el análisis pudiese contemplar un número adecuado de piezas y ampliar, así, los resultados de otros estudios revisados en el estado de la cuestión, que precisamente adolecían de esta carencia al centrarse en un periodo concreto dentro de un año.

Los anuncios del año 2017 fueron grabados directamente de la televisión, mientras que los demás se buscaron en los canales oficiales de cada una de las marcas, ya sea su propia página web o su canal en Youtube en España, de modo que pudiera determinarse con exactitud el año y su emisión en televisión. El análisis de contenido se realizó entre octubre y diciembre de 2017 a partir de 24 variables (ver tabla $n^{\circ}$ 3) aplicadas a una muestra de 60 campañas (ver anexo) elegidas al azar (Piñuel y Gaitán, 1998; Serrano Pascual, 2008; Ruiz Olabuénaga, 2012) con respecto a las emitidas en los últimos 5 años (2013-2017) por los 20 anunciantes objeto de estudio, que determinan el cumplimiento o no de cada una de ellas. En el caso de Wanabet e Interwetten, sólo se ha podido analizar un anuncio de cada marca por ser el único disponible en canales oficiales.

Este análisis de contenido codifica la presencia o ausencia de cada una de las variables y contempla tanto las directrices de los códigos de Autocontrol como sus resoluciones para que no exista subjetividad a la hora de que el evaluador, que ha sido el propio autor, codifique el cumplimiento o no de cada variable.

Este análisis no olvida "la construcción y legitimación de discursos sociales que afectan a la vida de las personas" (Benavides Delgado, 2012: 83) presente en la publicidad, por lo que se realiza también un análisis de contenido descriptivo de los casos de estudio representativos, que integra tanto los aspectos cumplidos como los incumplidos de forma notable.

\section{Resultados}

Los resultados obtenidos ponen de manifiesto numerosos incumplimientos en cuanto a la presencia de algunos elementos visuales e informativos relacionados con la responsabilidad social.

En primer lugar, aunque son pocos los anunciantes que señalan el nombre real del operador en sus anuncios, el $100 \%$ identifica al anunciante al indicar en la sobreimpresión en texto la web del mismo, que es precisamente la que conocen los usuarios y donde pueden consultar la denominación social completa. 
Figura 1. Sobreimpresión con la identificación del operador en 888 y Codere

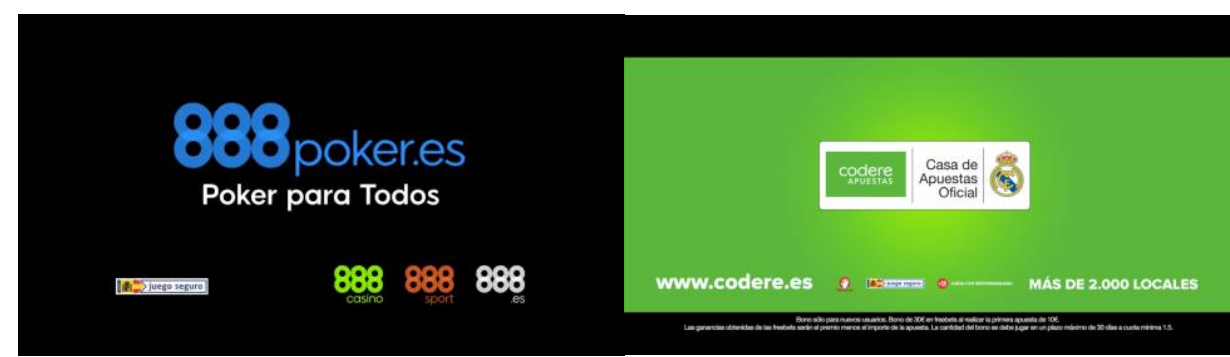

Fuente: emitido en televisión.

El $16,67 \%$ de los anuncios no incluye la sobreimpresión en texto "juega con responsabilidad", el 90,00\% tampoco incluye el logo de "jugar bien", el 20,00\% omite el logo "juego seguro", el 78,33\% no emplea el logo de "autoexclusión".

Con respecto al requisito legal de que la publicidad vaya dirigida a mayores de edad, el logo " +18 " no aparece en el $11,67 \%$ de los anuncios y en el $25 \%$ aparece en texto en vez de utilizar el logo específico, por lo que su presencia pasa más desapercibida.

Figura 2. Sobreimpresión +18 en Pokerstars y 888

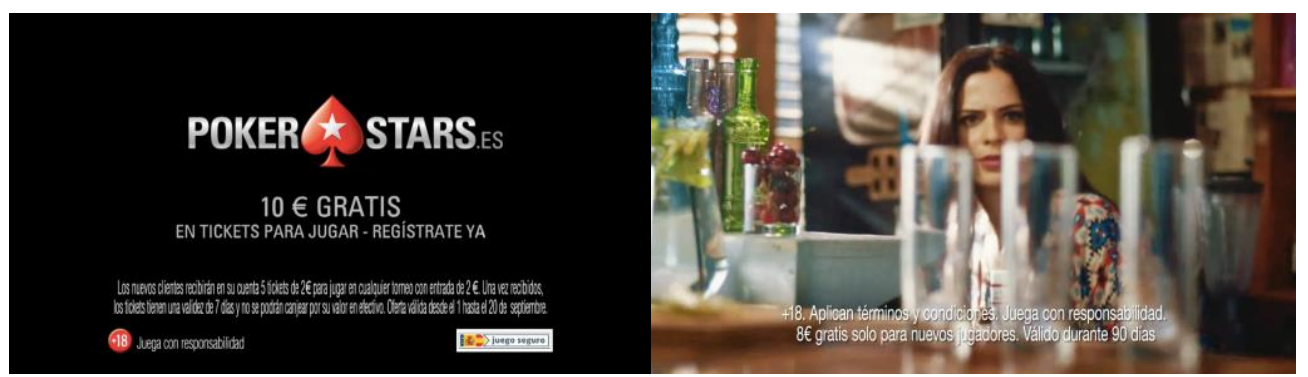

Fuente: emitido en television.

El menosprecio del trabajo o el estudio con respecto al juego, presente sólo en el 1,67\% de la muestra, es evidente en el anuncio de Pokerstars en el que un Usain Bolt recién retirado juega a Zoom en un plano en el que se aprecian sus míticas botas de oro ya colgadas, indicando que es más emocionante el juego que una carrera de 100 metros de atletismo con menos esfuerzo (tumbado en una amaca): "menos esperas y más acción". Aunque no alude directamente a su trabajo, contrasta con su cara dos días antes tras retirarse sin obtener ninguna medalla, tratándose, además, de un corredor sobre el que se ha escrito en múltiples ocasiones sobre su escasa disciplina en los entrenamientos a pesar de su talento.

Figura 3. Menosprecio al trabajo con respecto al juego en Pokerstars

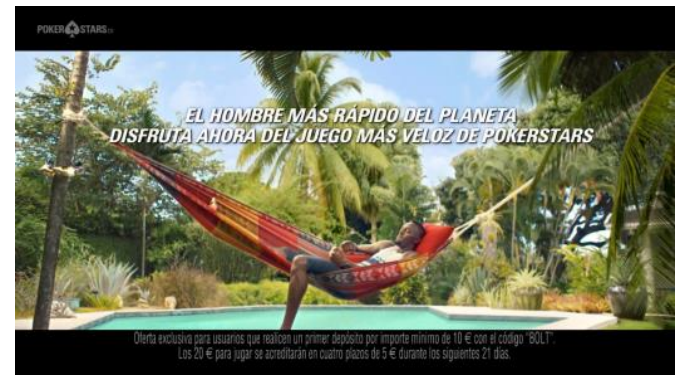

Fuente: emitido en televisión. 
Pokerstars es la única marca que sugiere la presión del grupo para jugar, presente en el 5,00\% del total los casos, o que permite inferir superioridad del jugador o inferioridad de quien no juega (3,33\% del total). En el primer caso, el tenista Rafa Nadal sale de un hotel jugando al póquer online con el móvil y una pareja que lo ve grita "jestá jugando al póquer!". De inmediato, decenas de personas acuden corriendo y ovacionan al tenista cuando hace el gesto de victoria acompañado de un "yes", en lo que claramente es una escena de aprobación social en la que se le encumbra no como deportista, sino como jugador de póquer. En el segundo, uno de los protagonistas cruza la mirada y sonríe en un gesto de complicidad y aprobación hacia los participantes de otras tres partidas de póquer antes de llegar a la suya, omitiendo así un ocio variado. Las tres personas que caminan hacia la azotea a jugar la partida principal aparecen reflejados con un estatus superior al ser el centro de atención, recibir las miradas de los demás y acudir a una mesa de póquer exclusiva para ellos en la azotea. Los propios gestos con la cabeza alta y la manera de andar realzan esa superioridad.

Figura 4. Sugerencia de la presión del grupo para jugar en Pokerstars

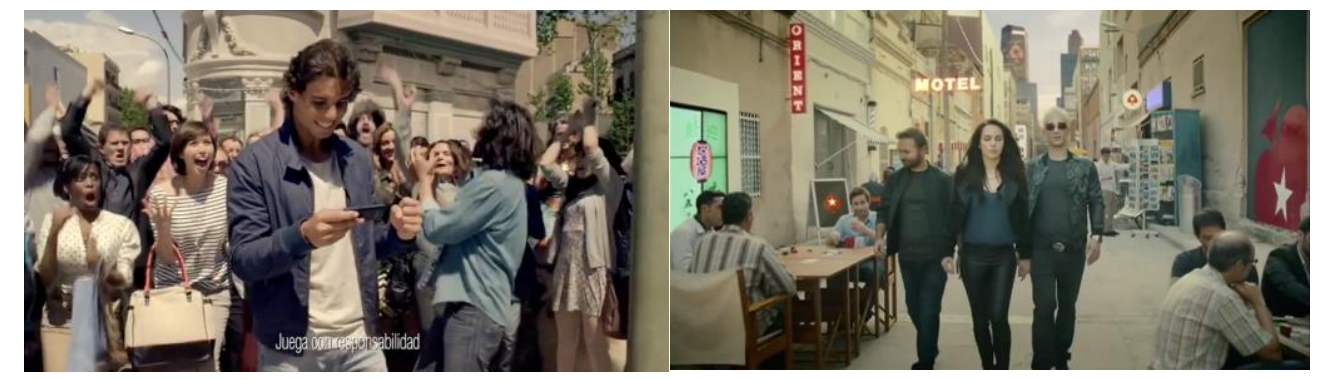

Fuente: emitido en televisión.

No existen incumplimientos notables en cuanto a alentar comportamientos relacionados con el juego irresponsable (5,00\%), presentar el juego como una solución a los problemas financieros $(1,67 \%)$, para recuperar las pérdidas del propio juego $(1,67 \%)$ o dar a entender que las pérdidas excesivas en el juego no tienen consecuencias (1,67\%), a pesar de que los ejemplos son llamativos.

Así, una prescriptora afirma que "puedes recuperar el $50 \%$ de lo que pierdas en Codere", dando a entender que, independientemente de lo que se pierda, "no es para tanto". En el caso de Canal Bingo, en una analogía de muy mal gusto entre las pérdidas de orina de una mujer de avanzada edad y las del juego, la protagonista afirma que "cada vez que gano me entran ganas de ir al baño y a veces no llego, pero desde que juego en casa con Canal Bingo, ya no me preocupo de las pequeñas pérdidas, sino de las grandes ganancias". Existe una clara relación entre las pequeñas pérdidas y seguir jugado para revertirlas y tener grandes ganancias.

Tampoco son afortunadas afirmaciones como "Pokerstars reparte más de un millón de euros en torneos de póquer cada semana", "gana hasta 500.000 euros en unos minutos" o "juega para ganar un millón de euros", puesto que parece que es un único jugador quien ha obtenido tal premio y que resulta sencillo ganarlo.

Aunque son mínimos los casos en los que se sugiere que jugar mucho $(0,0 \%)$ o la habilidad y experiencia del jugador (3,33\%) aumentan la probabilidad de ganar, encontramos cómo Codere sugiere que la habilidad o experiencia del jugador minimiza el azar. Al afirmar como eje central del anuncio que "si lo sabes y no apuestas, duele", con un claro gesto de tristeza con ojos llorosos tras recordar que había pronosticado la apuesta correcta, sugiere que la intuición conduce al éxito en la apuesta y eso llevaría a apostar siempre que uno cree que va a acertar, lo cual se acerca a conductas de riesgo relacionadas con el juego. 
Figura 5. Juego irresponsable en anuncios de Codere

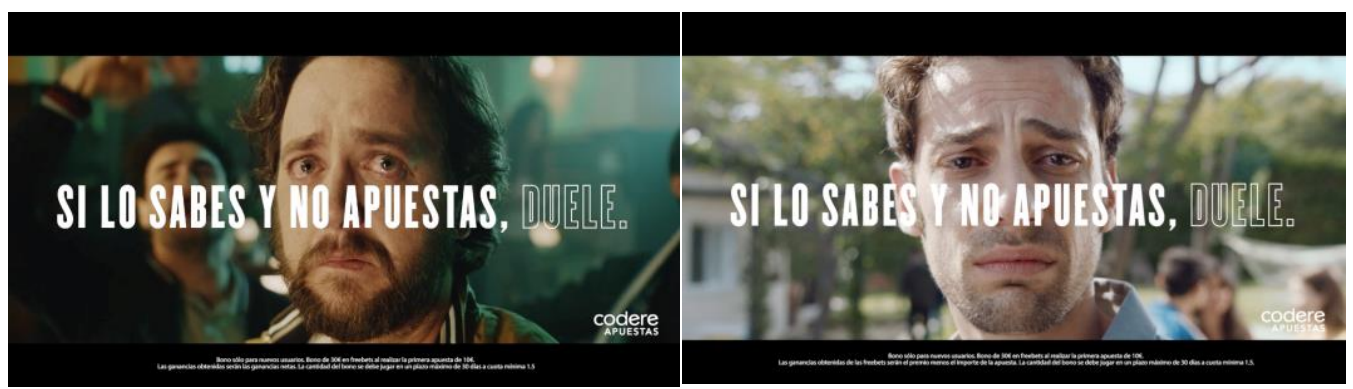

Fuente: emitido en televisión.

Pokerstars presenta la habilidad de Ronaldo con las fichas como un símil de la habilidad que tiene en su profesión y de la habilidad que está siempre presente del jugador de Póquer. Dado que es sutil, no explícita e indirecta la relación, no puede considerarse un incumplimiento, a pesar de que la confusión que crea parece deliberada. También parte de un anuncio genérico con el reto \#raiseit puesto de moda en redes sociales para retar a alguien a que demuestre sus habilidades, en este caso no relacionadas con el juego. Que un prescriptor como Cristiano Ronaldo rete en un anuncio de televisión a demostrar una habilidad junto al logo de Pokerstars está vinculando indirectamente el reto con los servicios que ofrece la marca.

Más controvertido es, a pesar de que utiliza un claro tono de humor y satírico, el caso de Pokerstars cuando parte de situaciones jocosas del pasado del protagonista, con aspecto crédulo, para afirmar: "Usa ese don, porque si puedes engañarte a ti mismo, puedes engañar a cualquiera".

En el caso de 888, la habilidad del jugador de póquer se alude indirectamente a través de la habilidad para barajar o repartir las cartas, siempre trasladando el mensaje de que eres un jugador preparado y que nada puede salir mal. Sin embargo, en otro anuncio de 888 el concepto de azar está muy reforzado con la imagen de una cuerda sujetando un peso que va quemándose poco a poco con un soplete, hasta que la cuerda se rompe y cae sobre una figura, que es la analogía del resultado de la máquina tragaperras.

Figura 6. Presentación de la habilidad del jugador en Pokerstars y 888

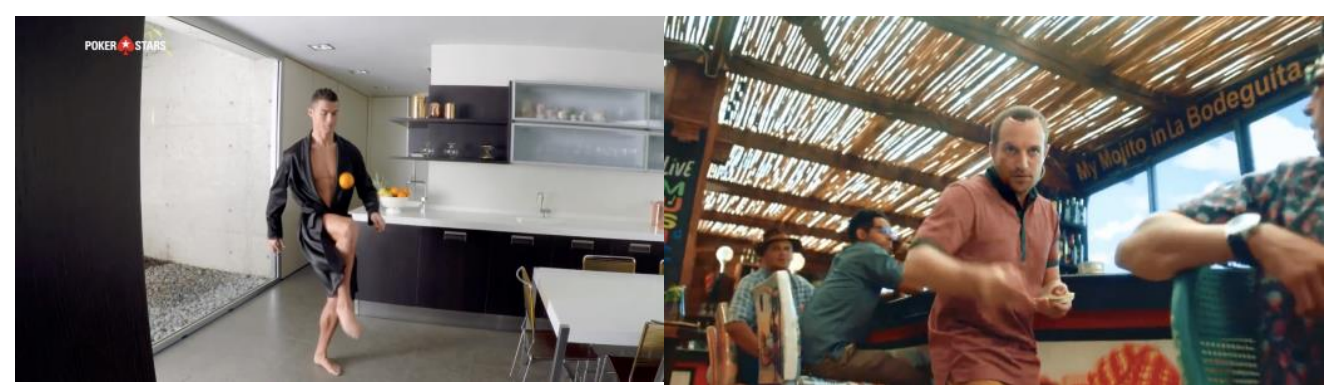

Fuente: emitido en televisión.

Otro incumplimiento poco significativo es el $1,67 \%$ de anuncios que muestra relaciones sociales o familiares como secundarias al juego. El hecho de que en algunos anuncios aparezca una persona sola jugando online no implica necesariamente que las relaciones sociales pasen a un segundo plano, puesto que recoge momentos habituales en los que una persona está aburrida y coge el móvil para entretenerse mientras hay anuncios en la televisión o el microondas calienta la comida, en el caso de Tómbola. Más discutible, aunque dentro de los parámetros razonables de cumplimiento, es el hecho de presentar una participación de los jugadores basadas en la interacción física, con cruces de sonrisas y una interacción 
social entre ellos, puesto que en la mayoría de los casos se ofrece la sensación de estar jugando con amigos de forma física, lo cual es irreal en el juego online, como en el caso de Pokerstars. Esta situación se minimiza con la aparición de algunas sobreimpresiones que emularían el contenido del dispositivo electrónico, pero siempre en segundo plano con respecto a la escena de juego físico.

Figura 7. Presentación de las relaciones familiares o sociales con respecto al juego en Tómbola y Pokerstars

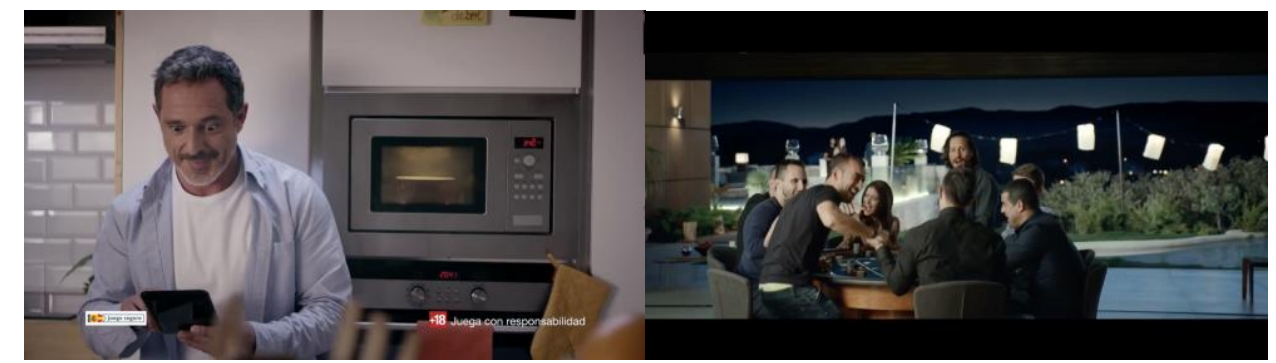

Fuente: emitido en televisión.

Es muy positivo que no se muestre explícitamente ningún contenido seductor con finalidad sexual $(0,00 \%)$, pero resulta sorprendente la discriminación manifiesta por género (6,67\%) o la aparición de 64 jugadoras sobre los 194 jugadores varones que aparecen en los anuncios (32,82\%). En algunos anuncios no se ve de forma definida el género de la persona, si es que aparece alguna, o quien sale no se identifica como jugadora, por lo que no aplica esta variable.

Aunque no hay estrictamente un contenido seductor con finalidad sexual, es totalmente innecesario que una de las mujeres que se incorpora a la partida lo haga en lo que parece una piscina en la posición que se muestra en la figura siguiente, abriendo el protagonista repentinamente los ojos y sonriendo a continuación. Codere, por su parte, realiza una parodia de una telenovela en la que se reproducen estereotipos de género en cuanto al papel de la mujer en el hogar que, aun en clave de humor, no deberían aparecer bajo ningún concepto. También es totalmente innecesario un primer plano de la esposa con un vestido completamente ceñido, el lenguaje con el que la interpela el marido, la aparición de su amante o la madre del protagonista besándose con el mayordomo. En otro anuncio de Codere y a pesar de que la prescriptora es una mujer, el mensaje es claramente sexista, en tanto que afirma haberse sometido a una operación para recuperar el $50 \%$ de su virginidad, haciendo una similitud con el $50 \%$ de lo que Codere te devuelve de las pérdidas.

Figura 8. Representación de género en 888 y Codere

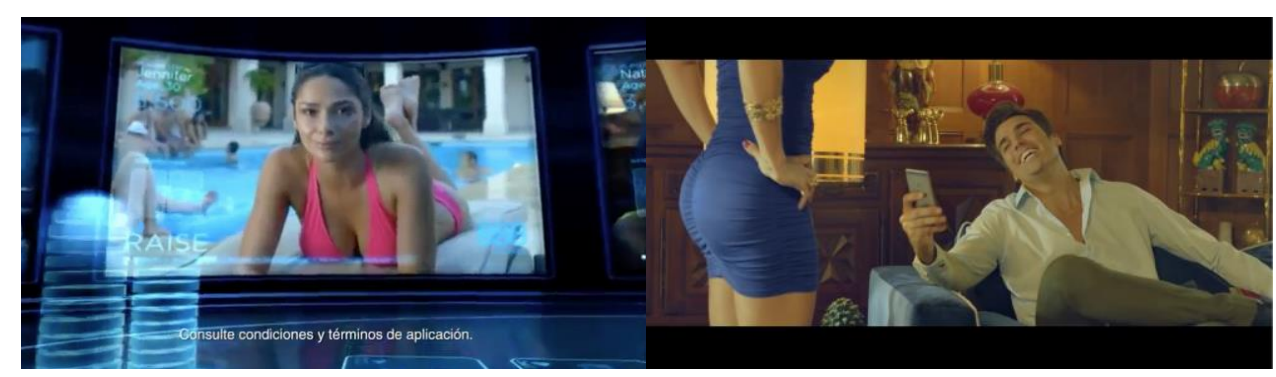

Fuente: emitido en televisión.

En otros casos, la igualdad en la representación se busca con la propia situación, a pesar de la inferioridad numérica de la mujer. Es el caso de 888, puesto que, aunque el jugador central es un hombre, tanto la mujer que se encuentra a un lado como el hombre que está al otro, miran la jugada de forma similar, con el detalle de que la mujer acumula más ganancias. Tómbola es el anunciante con mayor presencia femenina y, en la mayoría de las escenas, se comparte el juego en pareja. 
Figura 9. Representación de género en 888 y Tómbola

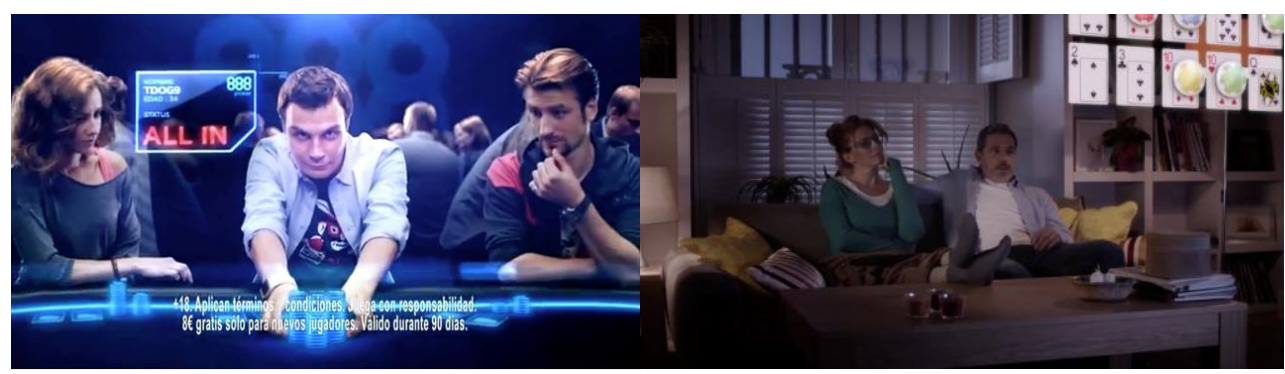

Fuente: emitido en televisión

Destaca, en último lugar, la agresiva política de bonos de bienvenida, descuentos o gratuidad ofrecidos para nuevos usuarios, presentes en el 68,33\% de los anuncios, en los que, además, no aparece la sobreimpresión con las condiciones básicas de ese "regalo" de bienvenida en el 6,67\% de los casos. En otros casos, aparecen textos como "juega ahora gratis" sin sobreimpresión o con contradicciones entre ésta y lo locutado por la voz en off. También resulta confuso cuando se indica en pantalla "juega gratis para ganar 1.000.000 $€^{\prime \prime}$, aun habiendo un asterisco de gran tamaño -curiosamente con una forma similar a una ficha de apuesta- que lleva a la leyenda "*6 $€$ gratis sólo para nuevos jugadores...", dado que cabe la duda de si esa cantidad es la que puede ganar un único jugador con una única jugada.

Figura 10. Bonos y condiciones en 888
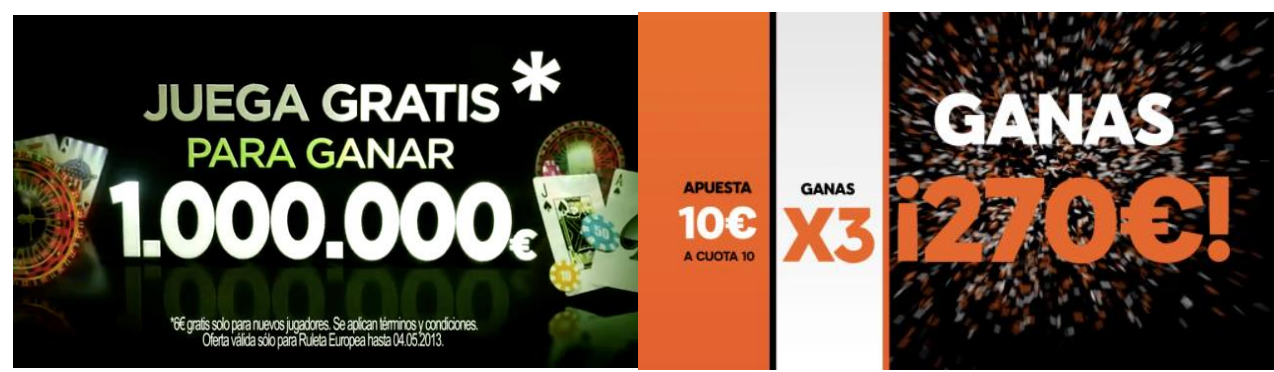

Fuente: Emitido en televisión.

El principio de veracidad también queda en entredicho debido a la ambigüedad en varios anuncios de Yobingo. Cuando se muestra la galería de ganadores del museo de Yobingo, la imagen sube rápidamente, dando la sensación de que el listado de ganadores es interminable, a pesar de que las fotografías de los supuestos ganadores están repetidas, volteando horizontalmente la imagen y cambiando el color de su ropa. Esta situación se refuerza con la frase "si quieres ganar, únete a mí", como si por jugar se ganara de modo causa-efecto. En otro de sus anuncios, la protagonista pasea por la calle mientras, a cada paso, se escuchan gritos de "me ha tocado", reforzado con fuegos artificiales, dando a entender que a casi todo el mundo le toca. A pesar de que los mensajes sobreimpresos indican "más de 4 millones de euros en premios" y "ya somos más de 50.000 ¡únete!", en ningún momento se indica el número de personas agraciadas. Hay que recordar que Autocontrol (2017a: 1) ha corroborado que no pueden darse consejos que induzcan a creer que aumentará la probabilidad de ganar con mensajes como "para que todas sus apuestas sean seguras y tengan el mayor éxito en la nueva aventura de las apuestas deportivas". 
Figura 11. Incumplimiento del principio de veracidad en Yobingo

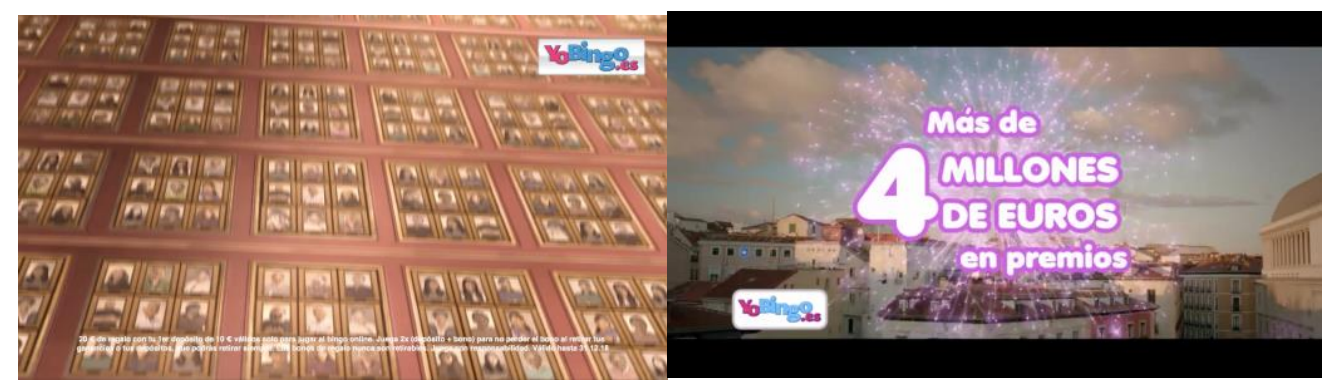

Fuente: Emitido en televisión.

Aunque existe actualmente una alta competitividad en el sector, no se ha encontrado publicidad desleal, únicamente algunas afirmaciones de publicidad comparativa como "la casa de apuestas más grande del mundo", especificando Bet365 en la sobreimpresión que se refiere a los ingresos, a pesar de no aportar el ranking en el que se basa, o Betfair, que indica que "en la fase de grupos de la Champions, Betfair ofreció mejores cuotas en más partidos que la competencia", especificando en la sobreimpresión que son "datos proporcionados por proveedor independiente Betradar".

Al analizar el detalle de cada anunciante, encontramos que Pokerstars es el único que realiza un anuncio genérico sobre la marca, sin anunciar específicamente ninguno de sus productos, fortaleciendo así su marca corporativa. Resulta significativo que no incluya en ninguno de sus anuncios el logo "jugar bien" ni el de "autoexclusión", no apareciendo, además, en el 30,00\% de sus anuncios el logo "+18" ni la sobreimpresión "juega con responsabilidad" ni el logo "jugar bien". En el 10,00\% de sus anuncios aparecen incumplimientos al menospreciar el trabajo o el estudio con respecto al juego, sugerir que la habilidad o experiencia del jugador minimiza el azar y discriminación explícita por género. El 20,00\% de sus anuncios muestra superioridad de quien juega y el 30,00\% sugiere la presión del grupo para jugar. En el $60 \%$ de sus anuncios se promocionan bonos de bienvenida, descuento o gratuidad, no indicando en el $20 \%$ de estos casos las condiciones básicas en la sobreimpresión. También es significativo que sólo aparezcan un 16,27\% de jugadoras con respecto a los jugadores.

Pokerstars aporta el estudio de caso más representativo en cuanto al tratamiento positivo que se ofrece al juego online como forma equilibrada de ocio. El anuncio The Game de Pokerstars con Neymar Jr. y Ronaldo, en el que un grupo de 8 amigos se divierten en casa jugando al póquer y al futbolín, con sonrisas cuando ganan, pero también cuando pierden. Además, uno de los protagonistas observa de camino a un grupo de jóvenes jugando al fútbol en la calle, por lo que se presentan distintas alternativas de ocio. Se observa claramente cómo el juego está vinculado a la interacción con los amigos como diversión e incluso uno de los participantes presta atención al perro en plena partida. Aunque sólo aparecen dos mujeres, no existe discriminación, ya que se presenta como un grupo heterogéneo con diferentes estéticas, sexos, la victoria se presenta tanto en hombres y mujeres y ambos juegan tanto al póquer como al futbolín.

En el caso de 888 , en todos sus anuncios incluye la leyenda " +18 " como sobreimpresión en texto y no el logo, como tampoco incluye en ninguno los logos de "jugar bien" y "autoexclusión", no apareciendo la sobreimpresión "juega con responsabilidad" en el 10,00\% de los casos. Los incumplimientos se sitúan en el $10,00 \%$ al alentar comportamientos relacionados con el juego irresponsable, presentar el juego como solución a los problemas financieros, presentar las relaciones sociales o familiares como secundarias al juego y utilizar la discriminación explícita por género. Las jugadoras están representadas en un 23,53\% con respecto a los jugadores. 
Tabla 3. Cumplimiento de variables analizadas en los anuncios de televisión de las marcas

\begin{tabular}{|c|c|c|c|c|c|c|c|c|}
\hline \multirow{2}{*}{ Variable } & \multirow{2}{*}{ Sí } & \multirow{2}{*}{ \% Sí } & \multicolumn{2}{|c|}{ No } & \multirow{2}{*}{$\%$ No } & \multirow{2}{*}{$\begin{array}{c}\text { No } \\
\text { aplica }\end{array}$} & \multirow{2}{*}{$\begin{array}{l}\% \text { No } \\
\text { aplica }\end{array}$} & \multirow{2}{*}{ TOTAL } \\
\hline & & & No & En texto & & & & \\
\hline $\begin{array}{l}\text { Modalidad (Póquer, Casino, } \\
\text { Apuestas deportivas, Bingo) }\end{array}$ & - & - & - & - & - & - & - & 60 \\
\hline $\begin{array}{lll}\text { Identifica } & \text { claramente } & \text { al } \\
\text { anunciante } & & \\
\end{array}$ & 60 & $100,00 \%$ & 0 & - & $0,00 \%$ & - & - & 60 \\
\hline $\begin{array}{l}\text { La sobreimpresión en texto es } \\
\text { legible según el Código }\end{array}$ & 52 & $86,67 \%$ & 0 & - & $0,00 \%$ & 8 & $13,33 \%$ & 60 \\
\hline $\begin{array}{l}\text { Aparece la sobreimpresión de } \\
\text { lucha contra la adicción "juega } \\
\text { con responsabilidad" }\end{array}$ & 50 & $83,33 \%$ & 10 & - & $16,67 \%$ & - & - & 60 \\
\hline Aparece el logo "Jugar Bien" & 6 & $10,00 \%$ & 54 & - & $90,00 \%$ & - & - & 60 \\
\hline $\begin{array}{llll}\begin{array}{l}\text { Aparece } \\
\text { Seguro" }\end{array} & \text { logo "Juego } \\
\end{array}$ & 48 & $80,00 \%$ & 12 & - & $20,00 \%$ & - & - & 60 \\
\hline Aparece el logo "+18" & 38 & $63,33 \%$ & 7 & 15 & $36,67 \%$ & - & - & 60 \\
\hline $\begin{array}{lll}\begin{array}{l}\text { Aparece } \\
\text { "Autoexclusión" }\end{array} & \text { logo } \\
\end{array}$ & 13 & $21,67 \%$ & 47 & - & $78,33 \%$ & - & - & 60 \\
\hline \begin{tabular}{ll} 
Alienta & \multicolumn{2}{l}{ comportamientos } \\
relacionados con el juego \\
irresponsable
\end{tabular} & 3 & $5,00 \%$ & 57 & - & $95,00 \%$ & - & - & 60 \\
\hline $\begin{array}{l}\text { Los mensajes menosprecian el } \\
\text { trabajo o el estudio con } \\
\text { respecto al juego }\end{array}$ & 1 & $1,67 \%$ & 59 & - & $98,33 \%$ & - & - & 60 \\
\hline $\begin{array}{l}\text { Sugiere la presión del grupo } \\
\text { para jugar }\end{array}$ & 3 & $5,00 \%$ & 57 & - & $95,00 \%$ & - & - & 60 \\
\hline $\begin{array}{l}\text { Existe contenido seductor con } \\
\text { finalidad sexual }\end{array}$ & 0 & $0,00 \%$ & 60 & - & $100,00 \%$ & - & - & 60 \\
\hline $\begin{array}{l}\text { Superioridad de quien juega o } \\
\text { inferioridad de quien no juega }\end{array}$ & 2 & $3,33 \%$ & 58 & - & $96,67 \%$ & - & - & 60 \\
\hline $\begin{array}{l}\text { Las relaciones sociales } 0 \\
\text { familiares se presentan como } \\
\text { secundarias al juego }\end{array}$ & 1 & $1,67 \%$ & 59 & - & $98,33 \%$ & - & - & 60 \\
\hline $\begin{array}{l}\text { El juego se presenta como } \\
\text { solución a los problemas } \\
\text { financieros }\end{array}$ & 1 & $1,67 \%$ & 59 & - & $98,33 \%$ & - & - & 60 \\
\hline $\begin{array}{l}\text { El juego se presenta como la } \\
\text { solución para recuperar las } \\
\text { pérdidas del juego }\end{array}$ & 1 & $1,67 \%$ & 59 & - & $98,33 \%$ & - & - & 60 \\
\hline $\begin{array}{l}\text { Da a entender que las pérdidas } \\
\text { excesivas en el juego no tienen } \\
\text { consecuencias }\end{array}$ & 1 & $1,67 \%$ & 59 & - & $98,33 \%$ & - & - & 60 \\
\hline $\begin{array}{l}\text { Sugiere que jugar mucho } \\
\text { aumenta la probabilidad de } \\
\text { ganar }\end{array}$ & 0 & $0,00 \%$ & 60 & - & $100,00 \%$ & - & - & 60 \\
\hline $\begin{array}{l}\text { Sugiere que la habilidad o } \\
\text { experiencia del jugador } \\
\text { minimiza el azar }\end{array}$ & 2 & $3,33 \%$ & 58 & - & $96,67 \%$ & - & - & 60 \\
\hline Realiza competencia desleal & 0 & $0,00 \%$ & 60 & - & $100,00 \%$ & - & - & 60 \\
\hline $\begin{array}{l}\text { Existe discriminación explícita } \\
\text { por género }\end{array}$ & 4 & $6,67 \%$ & 56 & - & $93,33 \%$ & - & - & 60 \\
\hline $\mathrm{N}^{\circ}$ jugadoras/jugadores & - & - & - & - & - & - & - & $64 / 194$ \\
\hline $\begin{array}{l}\text { Mensaje bono bienvenida, } \\
\text { descuento o gratuidad }\end{array}$ & 41 & $68,33 \%$ & 19 & - & $31,67 \%$ & - & - & 60 \\
\hline $\begin{array}{l}\text { Sobreimpresión con las } \\
\text { condiciones básicas del bono o } \\
\text { descuento/regalo }\end{array}$ & 38 & $63,33 \%$ & 4 & - & $6,67 \%$ & 18 & $30,00 \%$ & 60 \\
\hline
\end{tabular}

Fuente: Elaboración propia. 
Figura 12. Ejemplos de cumplimiento de juego como forma de ocio en Pokerstars

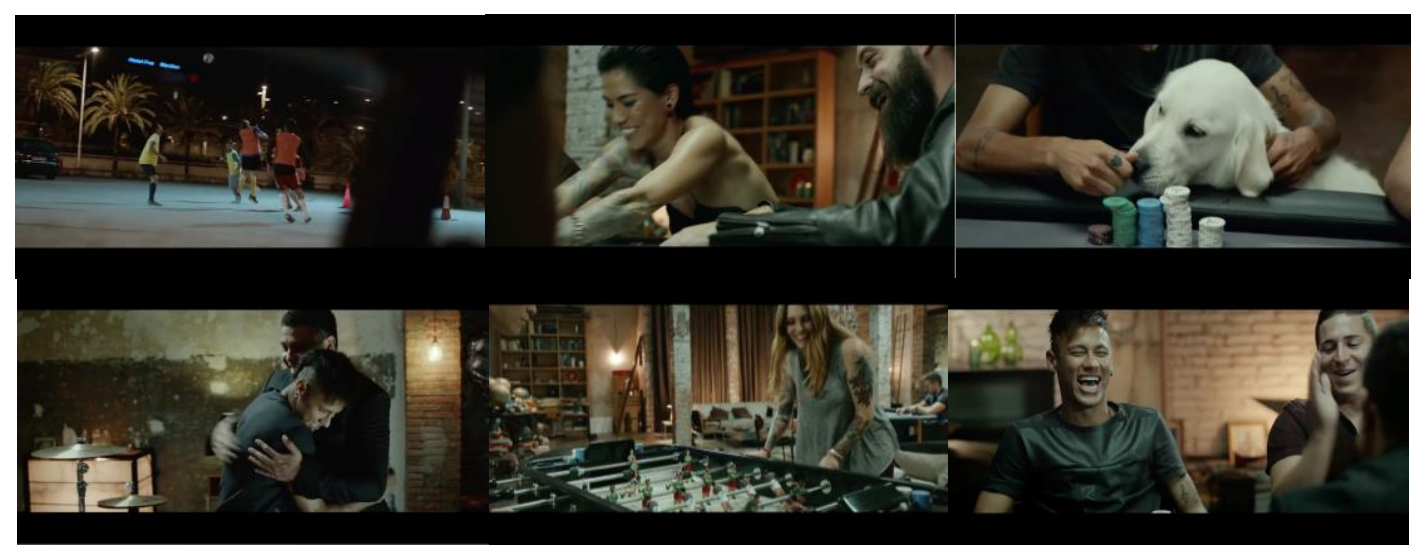

Fuente: emitido en televisión.

888 presenta un estudio de caso negativo al alentar comportamientos relacionados con el juego irresponsable, como es levantarse a las 2:00 de la cama para jugar al casino. Se plantea casi como una obligación al afirmar la voz en off "Ya es hora de que todo el mundo sepa cuál es su destino". Al despertarse la mujer y entrar en el salón, el marido se encuentra con un gesto de preocupación mirando la pantalla del ordenador ante su cara de estupefacción. Todo se vuelve alegría cuando comprueba que ha ganado un millón de euros, pero él lo celebra solo en el sofá y ella, a unos metros, lo celebra sola con las monedas que caen del cielo. La imagen de la mujer está totalmente estereotipada junto a la de la crupier. Mientras él lleva un típico pijama de cuadros, ella porta un camisón que claramente intenta realzar su atractivo, que, en un enfoque comparativo, resulta sexista.

Figura 13. Incumplimientos de 888

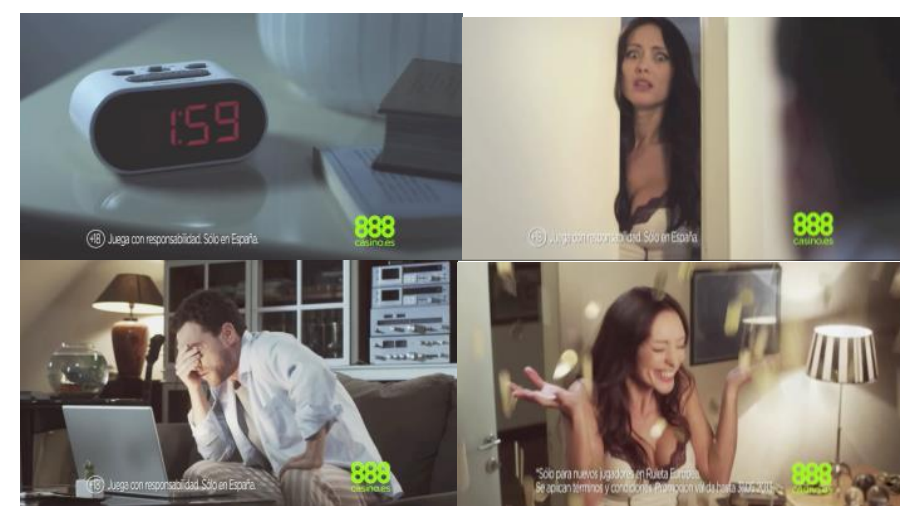

Fuente: Emitido en televisión.

Tómbola no incluye en ninguno de sus anuncios el logo de "autoexclusión", faltando el de "jugar bien" en el $60,00 \%$ y el de "juego seguro" en el $40 \%$ de los anuncios. Cumple con todas las demás variables íntegramente y en el $60 \%$ de los anuncios también recurre a ofertas de bienvenida, aunque con la correspondiente sobreimpresión de condiciones básicas. Tómbola presenta el mejor ejemplo en la promoción del juego responsable en todos sus anuncios, mostrando todos los logos y tomando como eslogan de cierre "por el juego responsable". Es el único anunciante, además, que muestra una heterogeneidad en la representación por género y que ha realizado una campaña específicamente destinada a promover el juego responsable, con frases como "jugar con cabeza es ponerse límites de tiempo y dinero [...] es saber cuándo parar para disfrutar al máximo de tu tiempo libre", momento en el 
que el grupo de amigos invita a una persona a dejar el móvil e incorporarse a la conversación, incidiendo en que hay que jugar para divertirse, "porque si no lo disfrutas, no es un juego", facilitando así el reconocimiento de síntomas de riesgo del juego irresponsable o compulsivo. En otros anuncios, la marca incide en el concepto de diversión, mostrando a los jugadores, indistintamente hombres y mujeres y de diferentes edades, provechando algún momento de descanso para jugar, como los anuncios en televisión o mientras se calienta la comida en el microondas. También se incita a chatear con los amigos que participan en el juego.

Resulta significativo que en ningún anuncio de Codere salga ninguna jugadora, con una discriminación explícita por género en el $40 \%$ de los anuncios. A pesar de ello, cumple estrictamente con los logos y las sobreimpresiones requeridas, a excepción del de "jugar bien", ausente en el 80\% de los casos. También incumple el $20 \%$ de sus anuncios al alentar comportamientos relacionados con el juego irresponsable y dar a entender que las pérdidas excesivas en el juego no tienen consecuencias. En todos sus anuncios incluye bonos de bienvenida, aunque sólo en uno de ellos no aparecen sobreimpresionadas las condiciones básicas.

Tanto Premier Casino como Yobingo coinciden en no utilizar el logo de "jugar bien". Sin embargo, mientras Premier Casino no tiene más incumplimientos, Yobingo tampoco incluye el logo de "jugar bien" en ninguno de sus anuncios ni la sobreimpresión de "juega con responsabilidad" en el 20,00\%. Ambos incluyen siempre bonos de bienvenida con sus correspondientes sobreimpresiones con las condiciones básicas.

Ni Sportium ni Carcaj ni Wanabet ni Canal Bingo ni Bet365 ni Interwetten incluyen el logo de "jugar bien". Tampoco el logo "autoexclusión" ni el de "+18", a excepción de Sportium (50,00\%), a pesar de que Canal Bingo, Bet365 e Interwetten sí incluyen como sobreimpresión en texto "+18". Sportium (50,00\%). Carcaj y Wanabet, además, omiten tanto la sobreimpresión "juega con responsabilidad" como el logo "juego seguro".

Canal Bingo realiza los dos incumplimientos más relevantes de esta sección: alentar comportamientos relacionados con el juego irresponsable y presentar el juego como la solución para recuperar las pérdidas del juego. Aunque la sobreimpresión cumple los requisitos del Código de Conducta en cuanto a legibilidad, su visibilidad no es óptima.

Carcaj, Wanabet y Bet365 no incluyen bono de bienvenida en ninguno de sus anuncios y Canal Bingo lo hace en el 50\%, frente a Sportium e Interwetten, que sí los incluyen en sus anuncios, todos ellos con la sobreimpresión de condiciones básicas asociada.

A pesar de la dispersión que supone analizar en último lugar un conglomerado de anunciantes como Betfair, William Hill, Bwin, Paf, Marca Apuestas, Luckia y Cirsa, sólo Paf, Marca Apuestas y William Hill (50,00\%) presentan un bono de bienvenida, que va acompañado de la correspondiente sobreimpresión de las condiciones básicas. Únicamente Bwin no incluye el logo "juego seguro" y Cirsa, la sobreimpresión de "juega con responsabilidad". Sí se encuentra más extendida la ausencia del logo "jugar bien" en William Hill, Bwin, Paf, Luckia y Cirsa y, además, el logo de "autoexclusión" en Marca Apuestas. 
Tabla 4. Cumplimiento de variables por cada marca en los anuncios de televisión

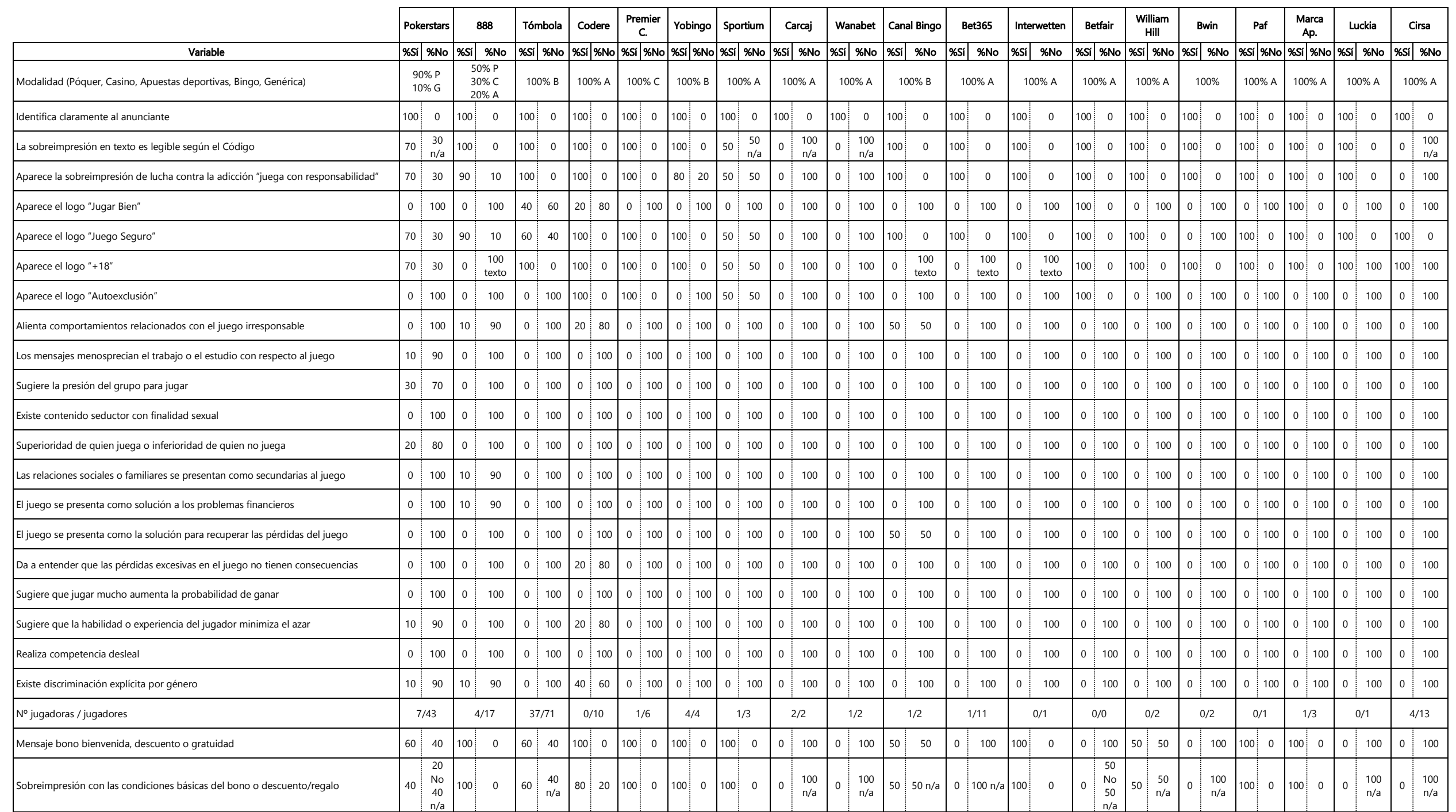

Fuente: Elaboración propia. 


\section{Discusión y conclusiones}

La importancia de los juegos de azar online como sector empresarial y el crecimiento que experimenta cada año la actividad publicitaria de las marcas operadoras no permiten obviar los especiales riesgos que pueden entrañar para la salud y la seguridad del patrimonio de los jugadores. Es necesario, por tanto, que los sistemas de autorregulación establezcan compromisos más allá de la legislación para proteger a los usuarios más vulnerables sin renunciar a la actividad que ejercen, siempre desde la perspectiva de la responsabilidad social.

En primer lugar, aunque todos los anunciantes se identifican con su nombre comercial y su página web, debería quedar totalmente clarificado en el Código de Conducta si es necesario incluir la denominación social de la empresa o algún otro dato para que la protección del consumidor sea plena.

Hay que considerar que, frente al tradicional achaque a la publicidad del sector de incitar a los colectivos vulnerables al juego, la publicidad de cualquier marca requiere de "un cierto tono de emoción vinculado a la apuesta [...] de forma responsable" (Autocontrol, 2017a: 1) y que la propia realidad del juego como forma de ocio, con una tensión previa al resultado seguida de sonrisas de los participantes, muchas veces famosos, y una música trepidante, son elementos que, por sí solos, no fomentan un tipo juego nocivo. De hecho, se presentan en la publicidad del sector alternativas de ocio al juego, como el fútbol, montar en monopatín, conversar... habitualmente en compañía. Otra cuestión es si todos estos elementos sirven para seducir, que evidentemente sí, y, por ello, un menor, que es especialmente vulnerable, no puede estar expuesto en el horario en el que se emite esta publicidad en televisión.

La visibilidad de los diferentes elementos recogidos en el Código de Conducta es de gran relevancia, especialmente en lo referido a la responsabilidad social de los operadores del juego. Lo es, en primer lugar, a la hora de garantizar la legibilidad de los textos que puedan recoger tanto las condiciones particulares de los denominados bonos de bienvenida, descuento o regalo, como las de los diferentes logos de responsabilidad, que, además, en algunas ocasiones no aparecen o pasan desapercibidas entre otros elementos de color, a pesar de cumplir con el tamaño y el tiempo de presencia establecidos.

El hecho de que en un número importante de anuncios no salga el logo de "juego seguro" va en detrimento de los propios operadores del juego y son los más interesados en utilizarlo, puesto que identifica a los operadores que están autorizados e identifican la seguridad de su plataforma en cuanto a privacidad, seguridad en los pagos o ausencia de virus informáticos, por lo que resulta totalmente incomprensible su ausencia, que suele ir relacionada a la ausencia del logo "jugar bien". En cualquier caso, y dentro de la especial sensibilidad que hay que tener con los colectivos vulnerables al juego, la sobreimpresión "juega con responsabilidad" y el logo de "autoexclusión" deberían estar presentes en la totalidad de los anuncios.

Resulta intolerable tanto la no presencia del logo específico " +18" como su sustitución por un texto sobreimpreso, de menor visibilidad, puesto que, además, acompaña al texto de las condiciones específicas del bono de bienvenida y el texto de "juega con responsabilidad". También habría que eliminar la expresión "para todos" en el caso de 888, puesto que, a pesar de la sobreimpresión "+18", lanza un mensaje contradictorio con la prohibición para los menores de edad.

También es totalmente contrario al Código de Conducta el hecho de no incluir ninguno de estos logos ni sobreimpresiones en la versión larga de los anuncios por considerarlas películas, aunque sí aparecen en la versión de 20" o 30" de los spots televisivos. Considerar, como hace Pokerstars, que sus films no son publicidad es obviar lo indicado en el Código de Conducta, máxime cuando éstas son una versión de mayor duración, siendo todos los demás elementos idénticos.

Aunque los comportamientos que alientan el juego irresponsable son minoría y, en ocasiones, no aparecen de forma totalmente explícita, deberían erradicarse por completo. Dar a a entender un comportamiento irresponsable relacionado con el juego en el que se prefiere seguir jugando al bingo antes de solucionar percances de higiene personal o lanzar mensajes desproporcionados en cuanto a los premios que se obtienen cada semana en total, puede llevar a confusión sobre esos hábitos e, incluso, al engaño sobre cuánto puede ganar un único jugador.

La cuestión anterior hay que conectarla con la sugerencia de que jugar mucho aumenta la probabilidad de ganar, que no se encuentra presente en la muestra analizada, pero que es discutible su presencia en clave de humor. Por el contrario, sí es más problemática la presentación de la habilidad del 
jugador como factor reductor del azar, como se observa claramente en los dos principales anunciantes del sector.

En cuanto a las cuestiones relacionadas con la identidad de género, hay que señalar que Autocontrol ha dictaminado que el hecho de que no exista paridad en el número de hombres y mujeres representados en la publicidad o que una mujer tenga una actitud negativa o tenga tareas de limpieza no es causa suficiente de incumplimiento si es "reflejo de una sociedad diversa y plural de hombres y mujeres de distintas razas y de diversos estatus" (Autocontrol, 2016b: 1). Considerando que la publicidad tiende a representar al perfil del público objetivo, podría justificarse una mayor representación del hombre en la publicidad al ser el $83 \%$ de los jugadores activos, pero, por la misma lógica, en el bingo online deberían aparecer mayoritariamente las jugadoras y no sucede así.

A pesar de que en las escenas analizadas se puede inferir una cierta intencionalidad seductora que no llega a ser sexual, cabe recordar que Autocontrol (2016: 6) ha dictaminado en otras ocasiones que de la aparición de una modelo en bikini no se derivan beneficios ni resultados encaminados al "éxito social". Resulta revelador, en cualquier caso, que la mujer sea la única en la escena que aparece en ropa de baño.

En los escasos ejemplos que proporcionan los resultados sobre publicidad comparativa, llama la atención que los anunciantes no hagan referencia a dónde pueden consultarse los estudios que avalan las afirmaciones. Cabe recordar que Autocontrol establece el principio de veracidad en la norma 14 del Código General y que en sus resoluciones ha puesto de manifiesto reiteradamente que el mensaje debe sustentarse en un estudio con valor probatorio y no en "un mero juicio estimativo" (Autocontrol, 2016a: 7), lo que plantea algunos reproches en términos de veracidad y publicidad engañosa, que se relacionan también con los constantes bonos de bienvenida y únicamente se explica en la sobreimpresión en texto las condiciones básicas. Hay que considerar que el hecho de ofrecer un regalo por el primer depósito para jugar a un bingo online no es suficiente para incitar a un juego adictivo o patológico (Autocontrol, 2016c), a pesar de las contradicciones entre los textos y la voz en off de algunos ejemplos.

Consecuentemente, la necesidad de autorregulación en un sector como el de los juegos de azar online, susceptible de ser una forma de ocio, pero también de causar perjuicios a la salud y al patrimonio de las personas, queda patente una vez revisados los diferentes comportamientos irresponsables que se muestran y la confusión que se podría crear en la persona expuesta ante su publicidad, especialmente los colectivos más vulnerables.

Aunque los resultados han puesto de manifiesto una cierta responsabilidad de la mayoría de los principales anunciantes del sector, representados en los resultados de este estudio, el sector de los juegos de azar online debe mejorar el contenido del código de autorregulación, incorporando cuestiones tan relevantes como la igualdad de género, la visibilidad de la información que protege responsablemente a los públicos y el fomento de las actitudes responsables de una práctica del juego como forma de ocio, disociada totalmente de la potencial adicción en la que puede convertirse, tal y como advierte la literatura en la materia.

Por todo ello, y a pesar de que el grado de cumplimiento del actual Código de Conducta es elevado, el análisis de contenido de su publicidad pone de manifiesto la necesidad de realizar una propuesta de actualización del mismo que recoja las peculiaridades del juego online con respecto a otras formas de juego tradicionales a partir de la inclusión de nuevas aportaciones:

Es necesario equiparar la publicidad responsable de todos los operadores de juego, sorteos y apuestas, independientemente de sus fines, incorporando la adhesión de SELAE y ONCE. También hay que considerar establecer un sistema de sanciones que gradúe en función de la gravedad del incumplimiento, siendo es prioritario ampliar el horario de prohibición de la difusión al de protección de menores, equiparando el bingo al resto de juegos online, manteniendo la excepción de la publicidad integrada los propios programas deportivos o de sorteos, aunque limitando el \% de anuncios sobre esta temática para evitar una asociación, por ejemplo, entre el fútbol y las apuestas, lo que supondría una banalización de los aspectos positivos derivados de la práctica deportiva y de los negativos del juego irresponsable. Tampoco puede obviarse la necesidad de establecer una cuota mínima de representación de género en la publicidad del sector. Adicionalmente, se debe establecer la obligatoriedad de que, al menos, el $10 \%$ de los anuncios de cada operador versen sobre la concienciación sobre el juego responsable. En último lugar, es imprescindible reforzar la protección al consumidor con los bonos y las condiciones de participación, que deben ser claros y consultables. 
La presente investigación está sujeta a las imitaciones propias de un estudio exploratorio cuyo objetivo es determinar la presencia o ausencia de las variables determinadas en la publicidad del sector. Por ello, una vez analizados los incumplimientos de los códigos de autorregulación del sector, las futuras líneas de investigación deben identificar la percepción de los públicos de tales incumplimientos en la publicidad de las marcas, de modo que pueda determinarse el grado en el que éstos pueden resultar afectados, considerando las especiales vulnerabilidades a las que pueden estar expuestos y las diferencias que puedan apreciarse entre los diferentes países.

\section{Referencias bibliográficas}

Autocontrol (2017): "Resolución de 14 de diciembre de 2017 de la Sección Tercera del Jurado: Particular (Confianza Online) vs. Euroconsultoría Formación Empresa S.L. 'Cursos Online gratuitos. Internet'", Autocontrol. Disponible en web: goo.gl/XW1tuA

- (2017a): "Resolución de 2 de noviembre de 2017 de la Sección Quinta del Jurado: Particular vs. Unidad Editorial S.A. 'Marca Apuestas. Internet'", Autocontrol. Disponible en web: goo.gl/XW1tuA

- (2016): "Resolución del recurso de alzada de Unión de Consumidores de la Comunitat Valenciana (UCCV) vs. Cortefiel S.A.", Autocontrol. Disponible en web: goo.gl/XW1tuA

- (2016a): "Resolución de 19 de abril de 2016 de la Sección Primera del Jurado: Beiersdorf, S.A. vs. Unilever España, S.A. 'Dove. El Mejor en Cuidado de la Piel'", Autocontrol. Disponible en web: goo.gl/XW1tuA

- (2016b): "Resolución de 29 de septiembre de 2016, de la Sección Sexta del Jurado: Particular vs. Sociedad Estatal Loterías y Apuestas del Estado S.A. 'Lotería de Navidad 2015 - La historia de Justino. TV'", Autocontrol. Disponible en web: goo.gl/XW1tuA

- (2016c): "Resolución de 3 de noviembre de 2016, de la Sección Segunda del Jurado: Particular vs. Volkswagen-Audi España S.A. 'Volkswagen Touran'", Autocontrol. Disponible en web: goo.gl/XW1tuA

- (2012): Código de Conducta sobre Comunicaciones Comerciales de las Actividades del Juego. Madrid: Autocontrol. Disponible en web: goo.gl/sdWA6b

- (2011): Código de conducta publicitaria (versión 26/04/2011). Madrid: Autocontrol. Disponible en web: goo.gl/y2XBS5

Benavides Delgado, J. (2012): "La investigación en comunicación y publicidad: nuevos temas y problemas", Questiones Publicitarias, 1 (17): 71-93. https://doi.org/10.5565/rev/qp.55

Buil, P., Solé Moratilla, M. J. y García Ruiz, P. (2015): "La regulación publicitaria de los juegos de azar online en España. Una revisión sobre la protección del menor", Adicciones, 27 (3): 198-204. Disponible en web: goo.gl/Qb2LTe

Chico, P. y Ruiz, M. (2013): "Empresas de juego y el patrocinio de actividades con especial referencia a los incentivos fiscales", en Palomar, A. y Baena, R. eds.: En torno al juego de azar: 409-459. Pamplona: Thomson Reuters. Disponible en web: goo.gl/yNKCML

Chóliz, M. (2016): "The Challenge of Online Gambling: The Effect of Legalization on the Increase in Online Gambling Addiction", Journal of Gambling Behavior, 32(2): 749-756. https://doi.org/10.1007/s10899015-9558-6.

Chóliz, M. y Lamas, J. (2017): "'¡Hagan juego, menores!' Frecuencia de juego en menores de edad y su relación con indicadores de adicción al juego", Revista Española de Drogodependencias, 42 (1): 34-47. Disponible en web: goo.gl/ci8QMG

Codere (2017, 8 de agosto): "Codere Apuestas lanza nueva campaña de publicidad y se pone en la piel del aficionado". Disponible en web: goo.gl/e4HA9q

Consejo Audiovisual de Andalucía (2017): Informe sobre la publicidad y promoción de actividades de juego en los servicios de comunicación audiovisual. Disponible en web: goo.gl/in1A4A

Consell de l'Audiovisual de Catalunya (2017): "Anàlisi de la presència de continguts en relació amb el joc i les apostes en línia". Disponible en web: goo.gl/tm3EUy

Derevensky, J. L. y Gupta, R. (2007): "Internet gambling amongst adolescents: A growing concern", International Journal of Mental \& Health Addiction, 5: 93-101. https://doi.org/10.1007/s11469-0079057-9 
DGOJ (2017): Mercado del juego online en España. Informe trimestral 4T 2017. Disponible en web: goo.gl/NnYE4i

- (2016): Memoria anual 2016. Madrid: Ministerio de Hacienda y Función Pública. Disponible en web: goo.gl/ZmEgvD

- (2016a): Análisis del perfil del jugador online. Informe 2015. Madrid: Ministerio de Hacienda y Administraciones Públicas. Disponible en web: goo.gl/eSzRMT

Gómez, J. A., Cases, J. I., Gusano, G. y Lalanda, C. (2017): Percepción social sobre el juego de azar en España 2017. Getafe: IPOLGOB-UC3M. Disponible en web: goo.gl/ur2QMj

Grun, L. y McKeigue, P. (2000): "Prevalence of excessive gambling before and after introduction of a national lottery in the United Kingdom. Another example of the single distribution theory", Addiction, 95: 959-966. https://doi.org/10.1046/j.1360-0443.2000.95695912.x

Lamont, M., Hing, N. y Gainsbury, S. (2011): "Gambling on sport sponsorship: A conceptual framework for research and regulatory review", Sport Management Review, 14: 247-257. https://doi.org/10.1016/j.smr.2011.04.004

Ley 13/2011, de 27 de mayo, de regulación del juego. BOE, 127, de 28 de mayo de 2011. Disponible en web: goo.gl/CN5k1s

Ley 7/2010, de 31 de marzo, General de la Comunicación Audiovisual. BOE, 79, de 1 de abril de 2010. Disponible en web: goo.gl/sovmHR

Ley 34/1988, de 11 de noviembre, General de Publicidad. BOE, 274, de 15 de noviembre de 1988. Disponible en web: goo.gl/qtA2y2

McMullan, J. y Miller, D. (2010): "Advertising in the 'new fun-tier': Selling casinos to consumers", International Journal of Mental Health and Addiction, 8: 35-50. https://doi.org/10.1007_s11469-0099201-9

Nutt, D. J., King, L. A. y Philips, L. D. (2010): "Drug harms in the UK. A multicriteria decision analysis", The Lancet, 376 (9752): 1558-1565. https://doi.org/10.1016/S0140-6736(10)61462-6

Orden EHA/3089/2011, de 8 de noviembre, por la que se aprueba la reglamentación básica del juego del póquer. BOE, 277, de 17 de noviembre de 2011. Disponible en web: goo.gl/fVRTrG

Orden EHA/3087/2011, de 8 de noviembre, por la que se aprueba la reglamentación básica del juego del bingo. BOE, 277, de 17 de noviembre de 2011. Disponible en web: goo.gl/EWjo5F

Orden HAP/1369/2014, de 25 de julio, por la que se aprueba la reglamentación básica de las apuestas cruzadas, y se modifican distintas órdenes ministeriales por las que se aprueba la reglamentación básica de determinados juegos. BOE, 184, de 30 de julio de 2014. Disponible en web: goo.gl/W96mVV

Piñuel Raigada, J. L. y Gaitán Moya, J. A. (1998): Metodología general. Conocimiento científico e investigación en la comunicación social. Madrid: Síntesis.

Real Decreto 1614/2011, de 14 de noviembre, por el que se desarrolla la Ley 13/2011, de 27 de mayo, de regulación del juego, en lo relativo a licencias, autorizaciones y registros del juego. $\mathrm{BOE}$, 275 , de 15 de noviembre de 2011. Disponible en web: goo.gl/9TZKCM

Ruiz Olabuénaga, J. I. (2012): Teoría y práctica de la investigación cualitativa. Bilbao: Universidad de Deusto.

Sánchez Revilla, M. A. (2017): Estudio Infoadex de la Inversión Publicitaria en España 2016. Madrid: Infoadex.

Serrano Pascual, A. (2008): "El análisis de materiales visuales en la investigación social: el caso de la publicidad", en Gordo López, A.J. y Serrano Pascual, A. coords.: Estrategias y prácticas cualitativas de investigación social: 245-286. Madrid: Pearson Prentice Hall. 
Anexo: Corpus de análisis

Tabla 5. Corpus de anuncios analizados

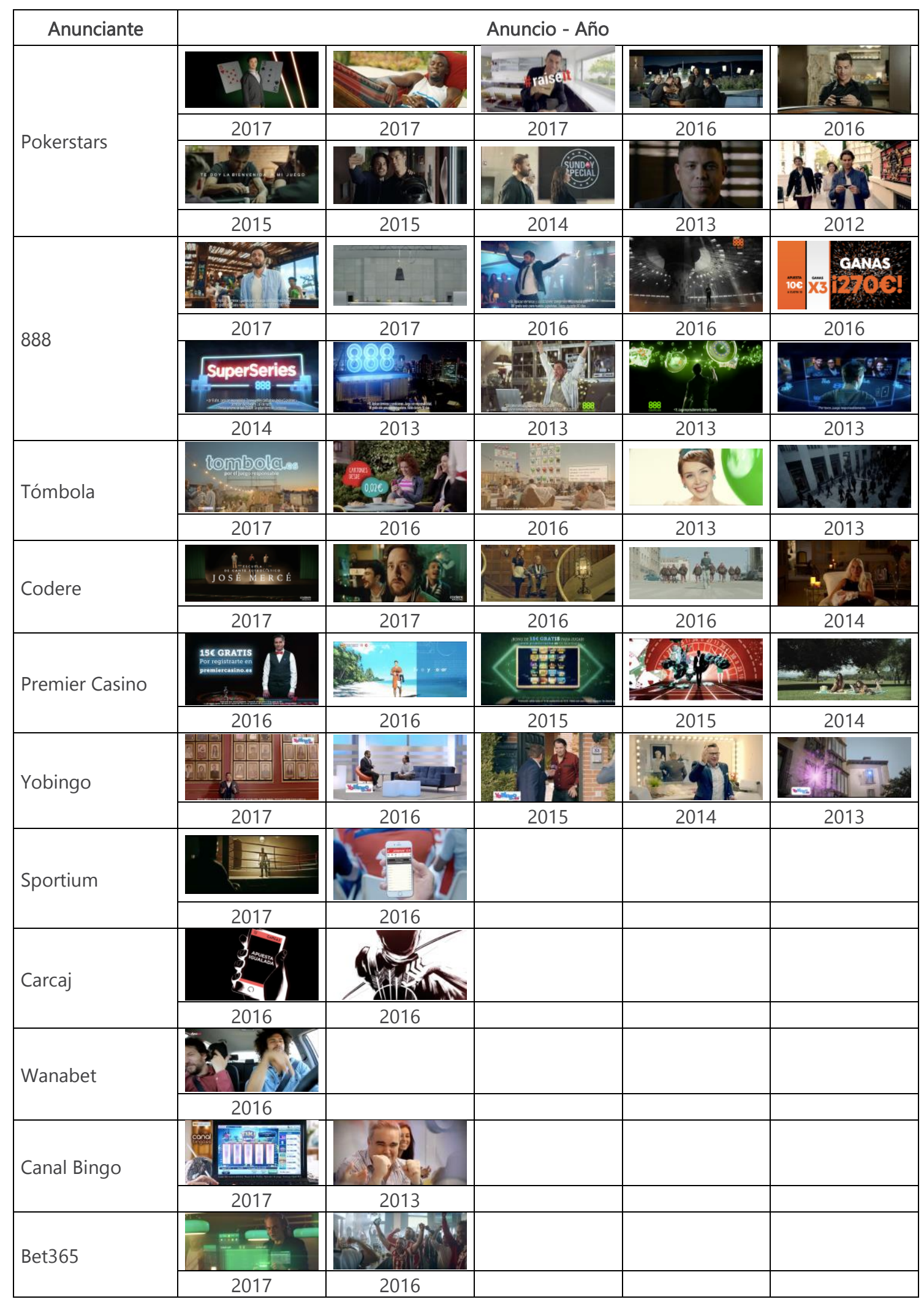




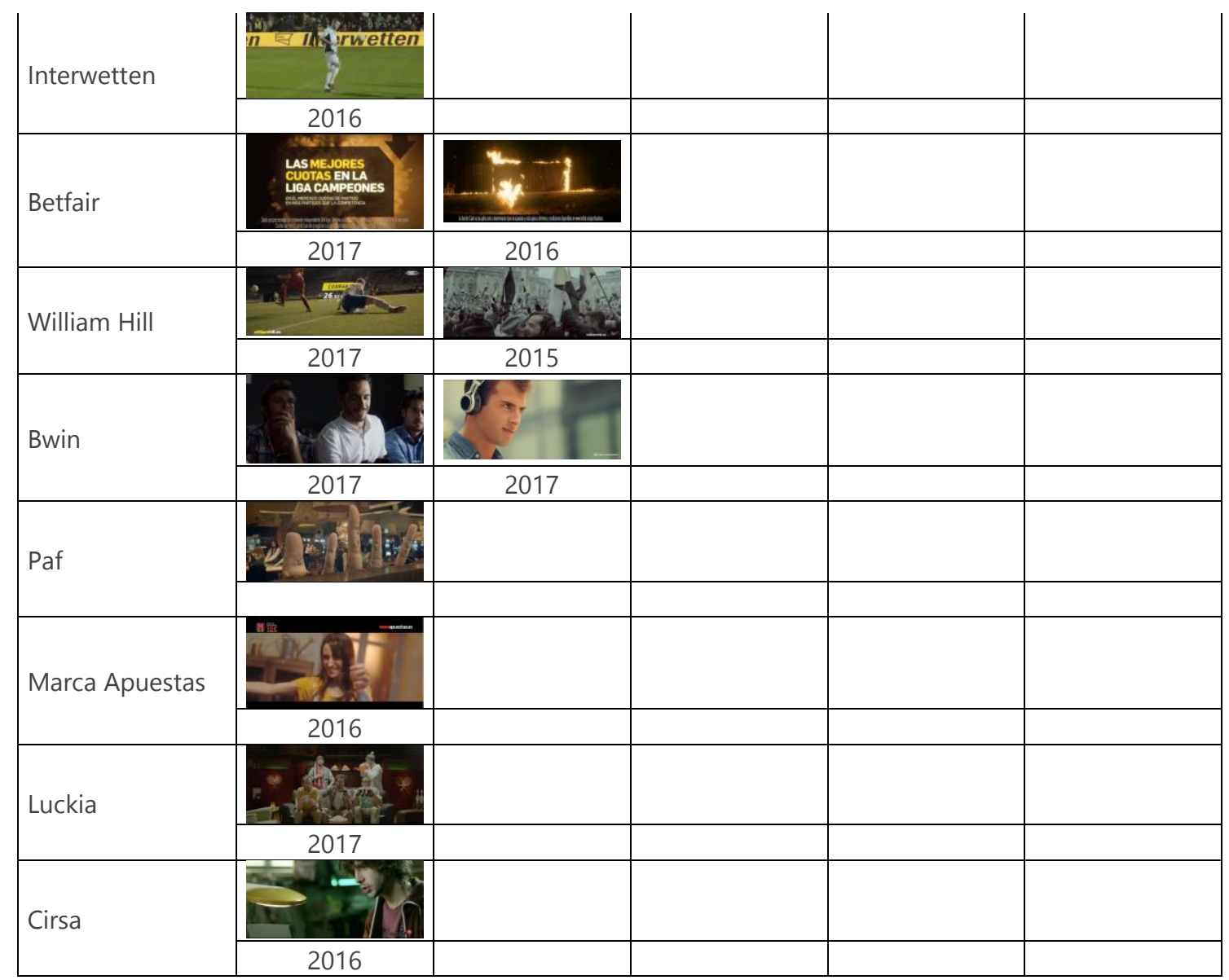

Fuente: Elaboración propia.

\section{Breve CV del autor}

Luis Mañas-Viniegra es Doctor en Comunicación Audiovisual y Publicidad. Es profesor asociado en la Universidad Complutense de Madrid (Departamente CAVP I) y miembro del Grupo de Investigación Complutense Gestión de las Marcas y los Procesos de Comunicación. 